\title{
Coinfection of High-Risk and Low-Risk Human Papillomavirus in Urethra Condylomata Accuminata
}

\author{
Lita Setyowatie, Noor Hidayah \\ Department of Dermatovenereology, Faculty of Medicine of Brawijaya University/Dr. Saiful Anwar \\ Regional Public Hospital, Malang, Indonesia
}

\begin{abstract}
Background: Condylomata accuminata (CA) is a sexually transmitted infection caused by the Human Papillomavirus (HPV), which has more than 40 subtypes classified into high and low risks. The incidence of coinfection involving HPVs in genitalia varies between $2 \%-71 \%$. Coinfection events increase in immunosuppressed patients. Purpose: To know the types of HPV in CA lesions and the risk factors of a high and low-risk HPV coinfection. Case: A 45-year-old woman presented with genital warts appeared three weeks before. The patient had a breast cancer history and undergone chemotherapy. The examination revealed multiple papules with verrucous surface, firm borders, with whitish color around the urethra and on the vaginal wall. Acetowhite test was positive. The biopsy examination showed squamous epithelium arranged to form papils and foci suspected as koilocytes suggesting CA. The Human Immunodeficiency Virus (HIV) rapid test, VDRL (Venereal Disease Research Laboratory) and TPHA (Treponema Pallidum Haemagglutination) examinations showed non-reactive results. The HPV deoxyribonucleic acid (DNA) genotyping test showed positive results for HPV type 56 (High-Risk Genotypes) and HPV type 6 (Low-Risk Genotypes). She was treated with electrosurgery and consulted to the urology department. Discussion: Coinfection of HPVs might cause a persistent HPV infection for a longer duration, as well as the risk of developing into cancerous lesion. The mechanism of high-risk and low-risk HPV coinfection in immunosuppressed individuals might be due to faster replication of the virus or reactivation of a latent infection. Conclusion: Coinfection of 2 types of HPV could happen in immunosuppression condition such as in patient undergone chemotherapy.
\end{abstract}

Keywords: Human Papilloma Virus, condylomata accuminata, genotyping test, urethra.

Correspondence: Lita Setyowatie, Department of Dermatovenereology, Faculty of Medicine of Brawijaya University/Dr. Saiful Anwar Regional Public Hospital Malang, Jl. Jaksa Agung Suprapto No. 2 Malang - Indonesia, phone: +628113393679, email: lita_centik@yahoo.com.

\section{INTRODUCTION}

Condylomata accuminata (CA) is a sexually transmitted infection (STI) caused by Human Papillomavirus (HPV). More than 40 types of HPV can infect human anogenital, and are classified into highrisk, probable high-risk, low-risk, and not-yetdetermined types. The high-risk type potentially develops into a cancerous lesion at a later time. ${ }^{1}$ Condylomata accuminata is frequently found in the genital and anal region in adults but rarely found in a female's urethra. ${ }^{2}$ According to a meta-analysis study in 2010, from 1 million women from 59 countries, the prevalence of genital HPV ranges from $1.6 \%$ to $41.9 \% .3,4,5,6$ A three-year study (2008-2011) in $\mathrm{H}$. Adam Malik Hospital Medan reported CA in 41 women $(53.9 \%)$ with an age range of $15-25$ years. ${ }^{7} \mathrm{CA}$ rarely develops in the urethral meatus. The urethra is only affected in about $20 \%$ of CA cases, in which $80 \%$ affects the meatus while the remaining $20 \%$ affects the proximal urethra. The involvement of two or more types of HPV infection in a genital lesion varies between $2 \%$ to $71 \%{ }^{8,9,10}$ A study by Brown et al. in 1999 states that most CA lesions comprise of several types of HPV, high-risk and low-risk, concurrently. ${ }^{11}$ There are several presumed risk factors for HPV coinfection, namely cigarette smoking, multiple sexual partners, and infrequent use of condoms. This coinfection might cause a persistent, longer duration of HPV infection and possible cancerous lesion at a later time. ${ }^{12}$ We present a case report of a 45-year-old woman with urethral CA caused by type 6 (low-risk type) and type 56 (high-risk type) HPV.

\section{CASE REPORT}

A 45-year-old woman presented with warts in the genital area 3 weeks before visiting the Dermatovenereology clinic of Dr. Saiful Anwar Regional Public Hospital (RSSA) Malang. The warts were initially a peanut size but enlarged rapidly in three weeks. There was no pain nor itchy sensation and it did not easily bleed. History of previous treatment were 
denied. The patient had no complaints of split stream, dysuria, or urethral bleeding.

The patient was diagnosed with breast cancer six years before and has had mastectomy and chemotherapy in 4 sessions. Two years later, she was diagnosed with uterine myoma, which was not treated because there were no complaints nor discomfort. The patient has been suffering from heart disease since 2015 and epilepsy for 18 years. She took depakote ${ }^{\circledR}$, clobazam, carbamazepine, flunarizine, spironolactone, and clopidogrel regularly as prescribed by a cardiologist and neurologist.

The patient was an employee in a cigarette factory assigned in the packaging division. She has been married for 18 years and sexually active with one sexual partner. Her spouse did not have a history of sexually transmitted infections.

The general examination showed that the vital signs were within normal limit. There was no evidence of lymph nodes enlargement on the inguinal. The dermatovenereology examination revealed multiple papules with a verrucous surface, well-demarcated borders, whitish, size $2.5 \times 2.5 \mathrm{~cm}$ on the urethral region, and $0.5 \times 0.5 \mathrm{~cm}$ on the vaginal wall (Figure 1).

The acetowhite test result with $3 \%-5 \%$ acetic acid was positive, marked by the color changes of the lesion into whitish color.

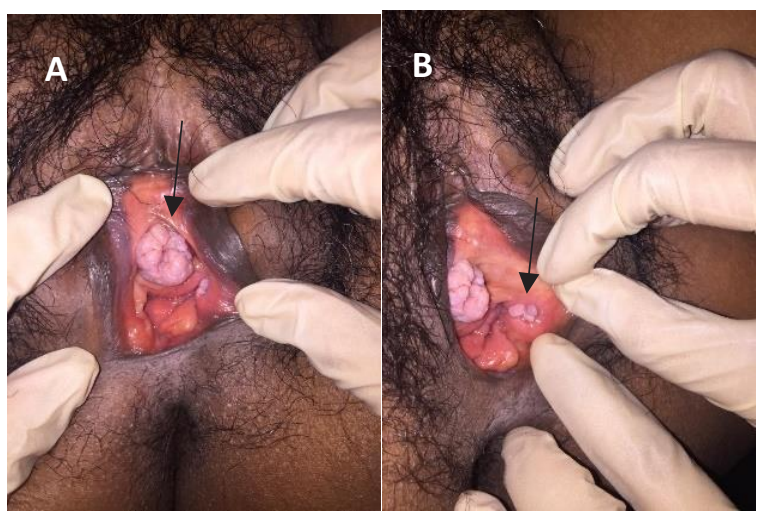

Figure 1. Dermatovenereology examination. Multiple papules with verrucous surface, welldemarcated borders, and whitish color $(\boldsymbol{\Lambda})$. A. Urethral orifice. B. Vaginal wall.

The histopathologic examination using hematoxylin and eosin staining revealed squamous epithelial cells arrangement, forming papilla and foci suspected as koilocytes suggesting CA. The patient was referred for a serological examination for HPV.

The Human Immunodeficiency Virus (HIV) rapid test, Venereal Disease Research Laboratory (VDRL), and Treponema pallidum haemagglutination (TPHA) test results were non-reactive. The Deoxyribonucleic Acid (DNA) Genotyping Test for HPV showed positive results for type 56 (High-Risk Genotypes) and type 6 (Low-Risk Genotypes) HPV.

The patient was diagnosed with condylomata accuminata and treated with electrosurgery. Gentamicin cream $0.1 \%$ was applied to the postelectrosurgery wound. The patient was then scheduled for a weekly follow-up.

After the electrosurgery, the lesions on vaginal wall were cleared, but there were some remaining lesions on the urethral orifice. (Figure 2). It was difficult to be reached due to its deeper location; therefore, the patient was then consulted to the urology surgery department. The complete urinalysis and urine culture examination results were normal. The patient was scheduled for re-observation in 3 months by the urology surgeons.

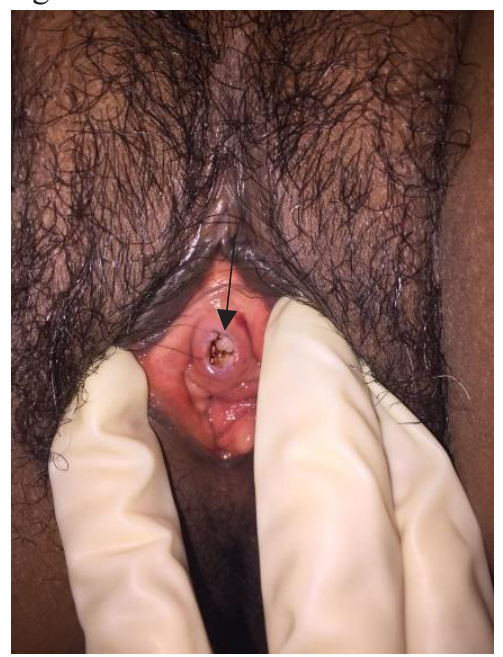

Figure 2. Post-electrosurgery. Papule with a verrucous surface, well-demarcated borders, whitish, $0,3 \times 0,3 \mathrm{~cm}$ in size on the periurethral region ( $)$.

\section{DISCUSSION}

CA consists of soft, papillary growths occurring singly or in clusters, and presents in moist areas such as the genitalia, rectum, and urethra caused by HPV infection, a double-stranded DNA virus. ${ }^{2,13}$ A HPV infection is most frequently transmitted through sexual intercourse and associated with various diseases, ranging from benign verruca vulgaris and CA or genital warts to malignant lesions such as cervical, vulvar, anal, and penile cancer. ${ }^{13}$ More than 40 types of HPV can infect human anogenital, and 15 of which are highrisk types (type 16, 18, 31, 33, 35, 39, 45, 51, 52, 56, $58,59,68,73$, and 82 ) that cause cervical cancer, 3 probable high-risk types (type 26, 53, and 66), 12 lowrisk types (type 6, 11, 40, 42, 43, 44, 54, 61, 70, 72, 81, and Cp6108), and 3 undetermined (type 34, 57, and $83){ }^{1}$

The incubation period for $\mathrm{CA}$ is three weeks to eight months. The lesion starts when a virus invades 
through a small injury on the skin or mucosa, followed by inoculation of the HPV virion to the basal epithelial cells. The virus rapidly replicates, triggering HPV gene expression. To cause an infection, HPV needs to be on a differentiating epithelium, whereas the basal epithelial cells are relatively undifferentiating. Therefore, the HPV virions migrate to a more superficial layer-the epidermis-right above the basal layer. Here, the HPV virions will start replicating, followed by the release of newly formed virion along with desquamated epithelium. The HPV virion will then infect other basal layers. The risk factors for CA are cigarette smoking, the use of oral contraception, multiple sexual partners, and sexual intercourse at an early age. ${ }^{14}$ Urethral condyloma is relatively uncommon in both males and females. Most urethral CA patients are asymptomatic, although complaints such as split urine flow, dysuria, urethral bleeding, and urinary tract infection are not entirely impossible. ${ }^{2}$

The clinical examination in this case revealed multiple papules with verrucous surface, welldemarcated borders, whitish, $2.5 \times 2.5 \mathrm{~cm}$ in size on the urethral region, and $0.5 \times 0.5 \mathrm{~cm}$ on the vaginal wall. According to its clinical presentation, the lesion was suspected as CA. The result of acetowhite test was positive. From the histopathologic examination, there were squamous epithelium arrangement forming papilla and foci presumed as koilocytes; suggesting CA. Based on these findings, the patient was advised for serological examination for HPV.

Histopathological examination in $\mathrm{CA}$ is recommended for women with a history of vulvar dysplasia, post-menopause, failure in medical therapy, doubtful clinical cases, and suspected malignancy. ${ }^{12}$ Koilocytes are pathognomonic cells in HPV infection in the form of cells with perinuclear cavity surrounded by dense cytoplasm but enlarged nucleus, hyperchromatic, wrinkled, and irregular chromatin. ${ }^{14,15}$ Histopathological examination was advised in this case due to the suspicion of malignancy. The examination result confirmed the presence of koilocytes; therefore, the lesion was suspected as CA, although further test to detect HPV DNA was needed to confirm the diagnosis. PCR test was done to detect HPV DNA. The result was positive for type $56 \mathrm{HPV}$ (High-Risk Genotypes) and type 6 HPV (Low-Risk Genotypes).

The HPV viruses can be divided into low-risk and high-risk types, depending upon their oncogenic potential. Infection low-risk or high-risk phenotype results in proliferative disease, but only the high risk phenotype causes malignant transformation. ${ }^{16}$

The HPV genome consists of 8 open reading frames, 6 early genes (E1, E2, E4, E5, E6 and E7) encoding the early protein and 2 late genes (L1 and L2) encoding the late protein. Early genes encodes no structural proteins involved in viral replication and oncogenesis, late genes encodes the L1 and L2 structural proteins. ${ }^{17}$

Proteins E5, E6 and E7 are thought to be associated with viral immune evasion. The E5 product can decrease the expression of histocompatibility leucocyte antigen (HLA) from infected cells, facilitating the release of viral immunity. E6 and E7 are considered tumorigenic genes, their product can bind to the tumor suppressor protein p53 and stop the cell cycle, impair apoptosis of infected cells and enhance their transformation. E2 represents the setting function for E6 and E7 transcription. The integration of the HPV genome into the host genome will disrupt the regulatory function of $\mathrm{E} 2$, leading to uncontrolled expression of E6 and E7, encouraging the development of normal cell cycle disorders and carcinogenesis. The expression of E6 and E7 is very important in high-risk HPV infection and development of cervical intraepithelial neoplasia (CIN). This expression of oncoprotein inhibits the immune system's response to high-risk HPV and helps persist the infection. ${ }^{17}$

A study by Brown et al. (1999) states that most CA lesions contain several types of HPV. With PCR, high-risk HPVs are detected in more than half of CA lesions from healthy individuals and $100 \%$ in specimens from immunosuppressed patients. The most common types of high-risk HPVs in immunosuppressed patients are type 16, 55, and 59. ${ }^{10}$ A number of factors allegedly related to HPV coinfection are smoking more than ten cigarettes per day and multiple sexual partners, and infrequent use of condoms as well. ${ }^{12}$

The mechanism of high-risk and low-risk HPV coinfection in immunosuppressed individuals might be due to faster replication of the virus. Reactivation of a latent infection might also be the underlying mechanism of HPV coinfection in immunosuppression. Moreover, multiple sexual partners might also be the causative factor due to the exposure to various types of HPV during one's lifetime. ${ }^{11}$ The causative factor for two types of HPV coinfection, in this case, was allegedly due to immunosuppression condition, in which the subject suffers from breast cancer with a history of chemotherapy.

A coinfection of HPVs might cause a persistent HPV infection for a longer duration, as well as the risk of developing into cancerous lesion at a later time. ${ }^{12}$ There are a number of therapy options for CA, namely the application of topical medicine, surgery, and systemic therapy. Centers for Disease Control (CDC) recommends cryosurgery using liquid 
nitrogen or podophyllin $10-25 \%$ for urethral CA. ${ }^{14}$ However, the current subject could not be treated with cryosurgery due to history of urticaria caused by cold temperature, which is a relative contraindication for cryosurgery. Podophyllin $10-25 \%$ was not possible as well due to its unavailability. The patient was, therefore, treated with electrosurgery.

Stone et al. (1990) compared several randomized controlled trials about the treatment of $\mathrm{CA}$, including electrodesiccation, cryosurgery and podophyllin. From this study, electrodesiccation is superior to cryosurgery and podophyllin. One of its advantages is the clearing rate of the lesion greater than $90 \%{ }^{18}$

In this patient, there was a small remaining lesion after the electrosurgery. Its deeper location made the lesion difficult to reach. The patient has been consulted to urology surgery department as well. The urology surgeons planned a re-evaluation in the following three months.

CA patients are suggested to refrain from sexual intercourse while the lesion remains, as well as using condoms during intercourse. Although condoms might not eliminate the chance of transmission, it reduces the risk of infection. This patient had type 56 HPV infection - a high-risk type. Type 56 HPV can be found in cervical cancer lesions. Its prevalence is between $1.1 \%-10.9 \% .{ }^{19}$ Albeit its relatively low prevalence, the patients still need further evaluation. The observation was done by urology surgeons in 3 months while routinely assigned for a pap smear every 6 months for early detection of cervical cancer.

As a conclusion, a urethral CA with high-risk and low-risk type HPV coinfection was reported in a 45-year-old female. A high-risk and low-risk HPV coinfection rarely occur in healthy individuals, yet frequently found in immunosuppressed conditions. Moreover, multiple sexual partners might increase the incidence of coinfection as well. In this case, the coinfection allegedly occurred due to the patient's immunosuppressed condition, in which she had a history of chemotherapy for breast cancer. In immunocompromised patient with persistent manifestation of CA, high-risk and low-risk type HPV coinfection should be suspected. Histopathological examination followed by PCR test would help establishing the diagnosis. Early diagnosis is important for early treatment to prevent the development of the lesion into malignancy.

\section{REFERENCES}

1. Baseman JG, Koutsky LA. The epidemiology of human papillomavirus infections. J Clin Virol 2005; (32): 16-24.

2. Chae JY, Bae JH, Yoon CY, Park HS, Moon DG,
Lee JG, Oh MM. Female urethral condyloma causing bladder outlet obstruction. Int Neurourol J 2014; 18(1): 42.

3. Bruni L, Diaz M, Castellsagué M, Ferrer E, Bosch FX, de Sanjosé S. Cervical human papillomavirus prevalence in 5 continents: meta-analysis of 1 million women with normal cytological findings. J Infect 2010 Dec 15; 202(12): 1789-99.

4. Tota JE, Chevarie-Davis M, Richardson LA, Devries M, Franco EL. Epidemiology and burden of HPV infection and related diseases: implications for prevention strategies. Prev Med 2011 Oct 1; (53): 12-21.

5. Forman D, de Martel C, Lacey CJ, Soerjomataram I, Lortet-Tieulent J, Bruni L, Vignat J, Ferlay J, Bray F, Plummer M, Franceschi S. Global burden of human papilloma virus and related diseases. Vaccine 2012 Nov 20; (30): 12-23.

6. Guan P, Howell-Jones R, Li N, Bruni L, de Sanjosé S, Franceschi S, Clifford GM. Human papillomavirus types in 115,789 HPV-positive women: a meta-analysis from cervical infection to cancer. Int J Cancer 2012 Nov 15; 131(10): 234959.

7. Aswar A. Karakteristik pasien kutil kelamin di RSUP Haji Adam Malik Medan Periode 20082011. Repository USU. 2012.

8. Spinillo A, Dal Bello B, Gardella B, Roccio M, Dacco MD, Silini EM. Multiple human papillomavirus infection and high grade cervical intraepithelial neoplasia among women with cytological diagnosis of atypical squamous cells of undetermined significance or low grade squamous intraepithelial lesions. Gynecol Oncol 2009 Apr 1; 113(1): 115-9.

9. Xie J, Ao C, Li J, Jiang L, Liu H, Zeng K. 5aminolevulinic acid photodynamic therapy for condyloma acuminatum of urethral meatus. J Dermatol Treat 2018:1-4.

10. Quint W, Jenkins D, Molijn A, Struijk L, van de Sandt M, Doorbar J, Mols J, Van Hoof C, Hardt K, Struyf F, Colau B. One virus, one lesionindividual components of CIN lesions contain a specific HPV type. J Pathol 2012 May; 227(1): 6271.

11. Brown DR, Schroeder JM, Bryan JT, Stoler MH, Fife KH. Detection of multiple human papillomavirus types in Condylomata acuminata lesions from otherwise healthy and immunosuppressed patients. J Clin Microbiol 1999; 37(10): 3316-22.

12. Nielson CM, Harris RB, Flores R, Abrahamsen M, Papenfuss MR, Dunne EF, Markowitz LE, Giuliano AR. Multiple-type human 
papillomavirus infection in male anogenital sites: prevalence and associated factors. Cancer Epidemiol Biomarkers Prev 2009; 18(4): 1077-83.

13. Erman-Vlahovic M, Vlahovic J, Mrcela M, Hrgovic Z. Coexistence of condylomata acuminata with warty squamous cell carcinoma and squamous cell carcinoma. Med Arch 2017; 71(1): 72-5.

14. Murtiastutik, D. Buku Ajar Infeksi Menular Seksual. Surabaya: Airlangga University Press; 2008.

15. Elliot J. Androphy, MD \& Reinhard Kirnbauer, MD. Human Papilloma Virus Infections. In Goldsmith LA, Katz SI, Gilchrest BA, Paller AS, Leffell DJ, Wolff K, editors. Fitzpartick's Dermatology in General Medicine. 8th Edition. New York: The McGraw-Hill Companies, Inc; 2012. p. 2421-33.
16. Doorbar J, Egawa N, Griffin H, Kranjec C, Murakami I. Human papillomavirus molecular biology and disease association. Reviews in medical virology. 2015; 25:2-3.

17. Song D, Li H, Li H, Dai J. Effect of human papillomavirus infection on the immune system and its role in the course of cervical cancer. Oncology letters. 2015;10(2):600-6.

18. Lacey CJ, Woodhall SC, Wikstrom A, Ross J. 2012 European guideline for the management of anogenital warts. J Eur Acad Dermatol 2013 Mar; 27(3): 263-70.

19. Prado JC, Calleja-Macias IE, Bernard HU, Kalantari M, Macay SA, Allan B, Williamson AL, Chung LP, Collins RJ, Zuna RE, Dunn ST. Worldwide genomic diversity of the human papillomaviruses-53, 56, and 66, a group of highrisk HPVs unrelated to HPV-16 and HPV-18. Virology 2005; 340(1): 95-1. 